\title{
Cross-cultural adaptation and psychometric validation of the World Health Organization quality of life-old module (WHOQOL-OLD) for Persian-speaking populations
}

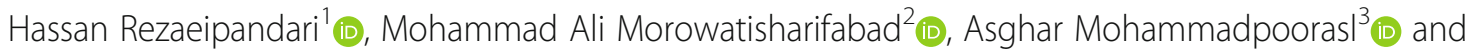
Abdolreza Shaghaghi ${ }^{1 *}$ iD

\begin{abstract}
Background: Reliable quality of life assessment is important for identification of health problems, evaluation of health interventions and planning of optimal health policies and care packages. Due to lack of a psychometrically robust measurement tool for quality of life appraisal among the Iranian older population, this study was aimed to investigate psychometric properties of the Persian version of the World Health Organization quality of life-old module (WHOQOL-OLD-P) for use on the Iranian and other Persian-speaking aged populations.

Methods: The standard translate/back-translate procedure was applied to convert the English version of the WHOQOL-OLD into Persian. The face and content validities were assessed by a panel of experts including 15 specialists in geriatrics and allied fields. The Cronbach's alpha and intra-class correlation (ICC) coefficients were estimated to assess internal validity and reliability of the translated version. Factorial structure of the WHOQOL-OLD$\mathrm{P}$ was also tested using confirmatory factor analyses in a sample of 400 Persian-speaking older adults (aged 60 years of old and above) residing in the city of Yazd, the capital city of Yazd province, center of Iran.

Results: The internal consistency and reliability indices of the WHOQOL-OLD-P were in the vicinity of acceptable range (Cronbach's alpha: $0.65-0.82$ and ICC: 0.90-0.98). The confirmatory factor analysis outputs confirmed the sixfactor solution of the WHOQOL-OLD-P (RMSEA $=0.04, \mathrm{CFI}=0.94, \mathrm{TLI}=0.93$, SRMR $=0.06$ ).

Conclusion: The study findings support validity and reliability of the WHOQOL-OLD-P for use on Iranian and possibly other Persian-speaking older populations. Further cross-cultural and comparative multinational studies are recommended to provide more vigorous evidence about feasibility and acceptability of the translated tool in diverse and multicultural Persian-speaking communities.
\end{abstract}

Keywords: Quality of life, Older adult, WHOQOL-OLD, Psychometric properties

\section{Background}

Quality of life (QOL) assessment is considered by health scholars as an important requirement for evidence based

\footnotetext{
* Correspondence: ar.shaghaghi@gmail.com

'Department of Health Education and Promotion, Faculty of Health, Tabriz University of Medical Sciences, Tabriz, Iran

Full list of author information is available at the end of the article
}

health care decision making and policy formulation for ageing population of the world. Therefore, QOL assessment is a part of routine health care packages in many countries to ensure effectiveness of health care or innovative interventions that targeted aged populations $[1,2]$.

The ratio of aged to overall population of Iran as a transitional country is rapidly increasing and based on

(c) The Author(s). 2020 Open Access This article is licensed under a Creative Commons Attribution 4.0 International License, which permits use, sharing, adaptation, distribution and reproduction in any medium or format, as long as you give appropriate credit to the original author(s) and the source, provide a link to the Creative Commons licence, and indicate if changes were made. The images or other third party material in this article are included in the article's Creative Commons licence, unless indicated otherwise in a credit line to the material. If material is not included in the article's Creative Commons licence and your intended use is not permitted by statutory regulation or exceeds the permitted use, you will need to obtain permission directly from the copyright holder. To view a copy of this licence, visit http://creativecommons.org/licenses/by/4.0/ The Creative Commons Public Domain Dedication waiver (http://creativecommons.org/publicdomain/zero/1.0/) applies to the data made available in this article, unless otherwise stated in a credit line to the data. 
the 2016 demographic census's results aged people constituted about $9.3 \%$ of the country's population [3]. Current pace of notable growth in the global ageing population demands an extensive source of health and social care. Therefore, without an intensive plan of action to address maintenance of aged people's health, the anticipated costs could be unaffordable for many countries, families and individuals [4].

QOL according to the World Health Organization (WHO)'s definition is the self-perception of individuals' current standpoint position in life with respect to what goals, expectations, standards, priorities, culture and value system they might have in their living ambience [5]. Thus, the concept of QOL could reflect many aspects of life [6] and its improvement might pose substantial effects on elder people's life. In consequence; QOL measurement was endorsed as a reliable priority index to provide information about integrity and competence of a health care system in responding to the transitional needs of an aging population.

Application of a reliable and explicit tool to measure QOL of elder people is an imperative prerequisite in health systems and also for conduction of robust research projects [7]. However; few instruments such as CASP 19 [8] and OPQOL-brief [9] have been introduced for use sparingly on a verity of methodological and applied grounds. The existent generic and disease-specific tools for QOL measurement, usually have limitations for application on aged people populations due to empirical evidence of measurement bias and little standardization [10].

The WHOQOL-OLD as an explicit measurement instrument for QOL assessment was introduced by the WHO [11] and has been validated for application in different languages and socio-cultural circumstances [1119] but not translated for use among Persian-speaking elder adults.

Preeminent advantage of the WHOQOL-OLD relative to other QOL assessment tools is its development through an extensive international cooperation [8] that makes its cross-cultural application and comparison of the results remissible. Being an old-age specific measure, not having other nonexclusive tools' impediments (e.g. being developed inherently for general or young age populations and problems arising due to the format of administration, consistency of responses) and its applicability for impact assessment of the public and health policies on elder people's quality of life are other superiority aspects of the WHOQOL-OLD. The instrument therefore; can be considered as a unique data collection tool that retain the required configuration for ascertainment of best investment areas to enhance quality of life in aged populations [8-11].

Main aim of this study was to translate and psychometrically appraise properties of the Persian version of the WHOQOL-OLD to provide a robust measurement instrument for application in akin studies of QOL on aged Persian-speaking populations in the Middle East region and other neighborhood countries. Thus, crosscultural and international comparisons of the findings from studies in different populations will be applicable.

\section{Materials and methods \\ Participants}

The study sample consisted of 400 older adults (200 Zoroastrian and 200 Muslim individuals) aged 60 years old and above who were registered in the two primary health care center in the city of Yazd, the capital city of Yazd province, center of Iran. The sample size was decided based on the recommended sample size (8 people per each of the instrument's items) [20] for performing the confirmatory factor analyses. The invited aged people for participation in the study were 480 registred Zoroastrians (260) and Muslim (220) dwellers of them 400 consented to cooperate in the study (particiaption rate (83.33\%).

The inclusion criteria were being permenant resident of the city of Yazd, having age equal to 60 or above, being diagnosed with at least one to three simulataneous chronic diseases, ability to speak and understand Persian language, not having considerable hearing loss to make interviews absurd and also not having a major cognitive problems which was assured based on the respondents' Abbreviated Mental Test scores (AMT) [21]. The study exclusion criteria composed of not willing to continue participation after giving informed consent, progression of a chronic disease that make participation in the study medically inconsistent or development of a severe disability that make the respondent epistemically dependent on others.

\section{Translation procedure}

Standard translation and back translation procedures were followed after formal permission from the WHO Quality of Life (WHOQOL) assessment group to prepare a preliminary draft of the WHOQOL-OLD-P [22, 23]. The original WHOQOL-OLD was first translated into the Persian language by the two professional translators, one of them was familiar with the study subject. At the next stage the translated draft was back translated into the English language and this back-translated version was compared side by side to the original WHOQOL-OLD in terms of clarity, common language use, conceptual equalization and quality of the overall translation. Any inconsistencies between the original and the translated version was resolved at this stage and the final Persian version was administered to a group of representative older people $(n=10)$ unfamiliar with the topic, to ask for their comments about vague items or 
phrases, format of the questions and response items. All the feedbacks were considered to ensure rapport and having an exactly equivalent translated version to the original WHOQOL-OLD.

\section{Content validity appraisal}

A panel of experts consisting 15 gerontologists, geriatricians, health education and promotion specialists, psychologists and nursing specialists were contacted for their comments about the simplicity, grammatical soundness, clarity and understandability of the WHOQOL-OLD-P. The Lawshe's Content validity index (CVI) and content validity ratio (CVR) were estimated based on the panelists feedbacks and values of $\mathrm{CVI} \geq 0.8$ [24] and CVR $\geq 0.49$ [25] were deemed acceptable. To ensure face and qualitative content validity of the WHOQOL-OLD-P it was also pilot tested on the 28 older adults for their comments about understandability of the questions and response items however; no important issue was mentioned.

\section{Reliability assessment}

The Cronbach's alpha coefficient of internal consistency and the Intra-Class Correlation (ICC) coefficient of reliability were calculated to assess performance of the WHOQOL-OLD-P and reproducibility of the data collection process.

\section{Instrument}

\section{WHOQOL-OLD}

The WHOQOL-OLD is a multidimensional measure of quality of life in older adults that consist 24 items in six domains [11]. The items' responses are scored on a Likert type scale ranging from 1 to 5 and a higher total score represents better quality of life. The six subscales of the instrument include the respondent's perception about his/her sensory abilities, autonomy, lifetime activities, social participation, intimacy with others, death and dying [11].

\section{Data collection}

Two trained and qualified interviewers were hired to collect data in face-to-face interviews from the Zoroastrian and their socio-economically matched aged Muslim counterparts who had been registered in the two purposefully selected urban health care centers.

\section{Data analysis}

The skewness and kurtosis of the collected data were tested for normal distribution, mean and standard deviation of the WHOQOL-OLD-P's scores were estimated consequently [26]. The ceiling and floor effects were also checked for detection of imbalance in the percentage of the study participants (greater than 20\%) with low and high levels of WHOQOL-OLD-P's scores and to assess ability of the instrument in discriminating the respondents across the high and low categories of quality of life [10]. The internal consistency reliability coefficient of Cronbach's Alpha and the intra-class correlation coefficient (ICC) to test the WHOQOL-OLD-P stability over time were estimated and values above 0.7 were deemed satisfactory $[27,28]$.

To verify compatibility of the study findings with the factor structure reported for the original WHOQOL-OLD module, confirmatory factor analysis (CFA) was performed and the CFA fit indices including Chi-squared/df $<$ 5.00, Standardized Root Mean Square Residual (SRMR) < 0.08, Comparative Fit Index (CFI), and Tucker Lewis index (TLI) $>0.90$ were deemed to be acceptable [29]. The IBM SPSS version 24 (IBM Corporation, Software Group, Armonk, NY, USA; 2016) [30], and STATA version 14 (Stata Corporation, College Station, TX: LP; 2015) [31] software were used for data analysis purposes.

\section{Results \\ Participants characteristics}

Mean age of the study participants was $70.63 \pm 8$ and their mean WHOQOL-OLD-P's scores was $77.72 \pm$ 10.41. Other characteristics of the respondents were presented in Table 1.

\section{Feasibility}

The study participants' overall and subscales' scores of the WHOQOL-OLD-P along with the test-retest reliability and internal consistency coefficients were tabulated in Table 2. The outputs of ceiling and floor effects' analysis for overall and subscales of the instrument were also presented in this table. As indicated the estimated values are in the range of acceptable range.

\section{Qualitative content and face validity appraisal}

The WHOQOL-OLD-P was sent to a panel of experts for their feedbacks about the instrument items' conceptual, cultural and linguistic appositeness. Based on the panelists' given scores to the listed items' attributes on a Likert type scale the CVI and CVR were estimated and the values were in the range of acceptable variability (0.88 and 0.86 respectively).

\section{Quantitative construct validity appraisal}

The conducted CFA in a sample of 400 Muslim and Zoroastrian older adults yielded an acceptable model fit with the six factor solution that was similar to the endorsed model fit for the original WHOQOL-OLD $\left(\chi^{2} /\right.$ $\mathrm{df}=1.92, P<0.001)$, RMSEA $=0.04, \mathrm{CFI}=0.94$, TLI $=$ $0.93, \mathrm{SRMR}=0.06$ ). 
Table 1 Demographics characteristics of the study participants $(n=400)$ in the cross-cultural adaptation and psychometric validation of the World Health Organization quality of life- old module (WHOQOL-OLD) for Persian-speaking populations

\begin{tabular}{|c|c|}
\hline Variables & $\mathrm{n}(\%)$ \\
\hline \multicolumn{2}{|l|}{ Gender } \\
\hline Male & $167(41.8 \%)$ \\
\hline Female & $233(58.2 \%)$ \\
\hline \multicolumn{2}{|l|}{ Marital status } \\
\hline Married & $288(72.0 \%)$ \\
\hline Non-married & $112(28.0 \%)$ \\
\hline \multicolumn{2}{|l|}{ Educational level } \\
\hline Illiterate & $71(17.7 \%)$ \\
\hline Primary school & $126(31.5 \%)$ \\
\hline Secondary school & $38(9.5 \%)$ \\
\hline High school diploma & $23(5.8 \%)$ \\
\hline Academic undergraduate degree & $104(26.0 \%)$ \\
\hline Academic postgraduate degree & $38(9.5 \%)$ \\
\hline \multicolumn{2}{|l|}{ Retirement status } \\
\hline Retired & $166(41.5 \%)$ \\
\hline Not retired & $234(58.5 \%)$ \\
\hline \multicolumn{2}{|l|}{ Living status } \\
\hline With spouse & $204(51.0 \%)$ \\
\hline With spouse \& children & $80(20.0 \%)$ \\
\hline With only unmarried children & $14(3.5 \%)$ \\
\hline With only married children & $40(10.0 \%)$ \\
\hline With other relatives/friends & $8(2.0 \%)$ \\
\hline Living alone & $54(13.5 \%)$ \\
\hline \multicolumn{2}{|l|}{ Morbidities } \\
\hline Hypertension & $250(62.5 \%)$ \\
\hline Cardiovascular diseases & $96(24.0 \%)$ \\
\hline Cancer & $16(4.0 \%)$ \\
\hline Pulmonary diseases & $48(12.0 \%)$ \\
\hline Diabetes & $161(40.3 \%)$ \\
\hline Osteoporosis & $107(26.8 \%)$ \\
\hline Arthritis & $237(59.3 \%)$ \\
\hline Hyperlipidemia & $177(44.3 \%)$ \\
\hline
\end{tabular}

\section{Discussion}

Main aim of this study was to verify psychometric properties of the WHOQOL-OLD-P for use on Persianspeaking older adults in Iran and probably other countries of the world. The study findings represented admissible reliability and construct validity of the instrument to be used for QOL assessment in research and conceivably in practice settings.

In the development of the original WHOQOL-OLD module, the interviewees' scores were considered to exhibit floor/ceiling effects on the basis of the percentage of the respondents with maximum or minimum total scores that exceeds 20\% [11]. The WHOQOL-OLD-P by this categorization, connoted no substantial floor and ceiling effects, indicative of its discriminant ability identical to the findings of the other WHOQOL-OLD crosscultural validation studies [14, 17, 19, 32, 33]. However; in a number of previous studies a tendency towards ceiling effect $[11,34,35]$ in measurement of well-being, life satisfaction and QOL was suggested due to probability of rampant positivity bias [8].

The estimated internal consistency measures of reliability (Cronbach's alpha coefficient) for the total and subscales of the WHOQOL-OLD-P in the present study were in the acceptable range (>0.7) [40] which is somehow consistent with the findings of other psychometric studies of the WHOQOL-OLD module on other sociocultural contexts $[11-17,19,36]$. The only observed incongruity among the conducted validation studies were low estimated internal consistency measure of the Cronbach's alpha for the "social participation" subscale in the Australasian study [37], for the autonomy subscale in the Spanish, German and Turkish studies [12, 17, 19] and for the "past, present and future activities" subscale in the Norwegian study [15].

The calculated ICC measure of reliability over time for both the total WHOQOL-OLD-P and its subscales' scores were in the vicinity of acceptable range [28] and similar to the findings of two other validation studies of the WHOQOL-OLD $[8,16]$.

The identified 6-factor solution that best fitted the study data was congruent with the reported priori factor structure of the original scale [11] and in the validation study of the Dutch version of the WHOQOL-OLD [38], however; the hypothesized model structure of the instrument in other studies $[12,13,15,16,19,32]$ were incompatible.

Regarding the obtained results in this validation study, it can be concluded that the WHOQOL-OLD-P's application is feasible since no problem encountered in the data collection stage and a relatively limited time frame (6-8 min for older adults with academic education and 10-13 min for the rest of interviewees) was required to complete the scale on every individual participant.

\section{Study limitations}

The study sample in this research consisted of elder people with at least one to three diagnosed simultaneous chronic diseases who had been registered in the two primary health care centers in the city of Yazd, the capital city of Yazd province, central part of Iran. The purposively selected health care centers and therefore, non-probabilistic sample that was selected for inclusion might be limited representativeness of the study participants and restraint extrapolation 
Table 2 The WHOQOL-OLD-P overall and subscales' scores of the study respondents in the cross-cultural adaptation and psychometric validation of the World Health Organization quality of life- old module (WHOQOL-OLD) for Persian- speaking populations

\begin{tabular}{|c|c|c|c|c|c|c|c|c|c|c|}
\hline WHOQOL-OLD-P subscales & $\begin{array}{l}\text { Minimum } \\
\text { score }\end{array}$ & $\begin{array}{l}\text { Maximum } \\
\text { score }\end{array}$ & $\begin{array}{l}\text { Mean } \\
\text { score }\end{array}$ & SD & Skewness & Kurtosis & $\begin{array}{l}\text { Floor } \\
(\%)\end{array}$ & $\begin{array}{l}\text { Ceiling } \\
(\%)\end{array}$ & $\begin{array}{l}\text { Cronbach's } \\
\text { a }\end{array}$ & ICC \\
\hline Sensory abilities & 4 & 20 & 13.98 & 3.16 & -0.39 & -0.09 & 0.5 & 1.3 & 0.83 & 0.95 \\
\hline Autonomy & 4 & 20 & 12.67 & 2.63 & -0.18 & 1.03 & 0.8 & 1.3 & 0.75 & 0.95 \\
\hline Death and dying & 4 & 20 & 10.89 & 4.10 & 0.34 & -0.48 & 8 & 3.8 & 0.83 & 0.98 \\
\hline Social participation & 5 & 20 & 13.45 & 2.54 & -0.38 & 0.68 & 0.3 & 1.5 & 0.73 & 0.98 \\
\hline $\begin{array}{l}\text { Past, present and future } \\
\text { activities }\end{array}$ & 6 & 20 & 13.52 & 2.38 & -0.09 & 0.67 & 0.5 & 1.3 & 0.80 & 0.95 \\
\hline Intimacy & 4 & 20 & 13.20 & 2.93 & -0.33 & 0.45 & 1.3 & 1.8 & 0.78 & 0.90 \\
\hline Total & 44 & 114 & 77.72 & 10.44 & -0.22 & 0.87 & 0.3 & 0.3 & 0.82 & 0.91 \\
\hline
\end{tabular}

and generalizability of the findings. Comparison of the within-subjects perceived QOL measures and association of the factors such as religion, age, gender, level of education and overall health status with the estimated QOL values were not speculated in this study. Therefore; interim data collection and analysis in future corresponding studies could add further detail and explanation about precipitating factors of QOL.

Iran is a multi-cultural, multi-religious and multiethnic country and the study findings might not be generalizable to elder people residing in the country's other provinces and geographical areas due to sociocultural diversities.

There is also possibility of the reporting bias based on the respondents' willingness and ability to provide accurate responses especially concerning the length of the WHOQOL-OLD-P, although the concern was attempted to be mitigated by emphasis on the anonymity of the participants and allocation of proper time for interview.

Elder people who suffer from multiple chronic diseases are more likely to develop depression and therefore; tend to report lower quality of life [38]. Such an impediment must be taken into account in interpretation of the study data.

Multidimensional nature of QOL and the effects posed by certain underlying factors warrant further research to examine how these circumstances might relate to selfreported quality of life among older people. QOL assessment by use of measures that actually highlight specific domains e.g. physical, emotional and social functioning or over emphasis on health-related aspect of daily life experiences may also cause bias especially in measurement of elder population's QOL [39]. Aged people themselves, might have a priority need or interest that could potentially be reflected in their responses to the items of QOL assessment instruments. The judgmental approach (which entails comparison between the respondents' state in different time frames e.g. present to past) which is salient generally in health related quality of life assessment tools could also further contribute to ambiguity in reliable determination of QOL. A number of other baseline socio-demographic factors e.g. gender, being divorced, unemployed, migrant and bereaved might also have same or even higher impact on several dimensions of perceived QOL in aged populations [39]. All these facets warrants interpretation of the QOL data with caution.

Introduction of a valid and reliable instrument for measurement of quality of life among Iranian and other Persian-speaking elder adults was the primary objective of this study. Taking into account all above mentioned limitations, the WHOQOL-OLD-P application could be recommended as an explicit instrument for measurement of perceived QOL as a proxy measure of aged people's overall health in the Iranian and other Persianspeaking elder populations across the world. The WHOQOL-OLD-P application could enhance reliability of QOL assessment by a wide range of healthcare providers (HCPs) (e.g. nurses, psychologists, geriatricians) in primary health care centers, secondary and tertiary care providing settings (e.g. nursing homes, day care centers and hospitals). The instrument can be utilized in routine care provision activities or in assessment of influences a specific health condition or morbidity and also subsequent restorative therapeutic intervention might have on perceived overall QOL among the aged people. Other social care providing organizations could also use the WHOQOL-OLD-P for estimation of impacts their policies, services or targeted interventions might have on elder people within the Persian-speaking countries.

\section{Conclusions}

The WHOQOL-OLD module was translated into Persian in this study and psychometrically tested for possible application in the research and practice settings within the Iranian context. The translated version indicated robust internal consistency, reliability and construct validity. Due to growing number of aged population in Iran presence of 
sound data collection tool for QOL assessment will add to the accuracy of scientific knowledge and intervention modalities that target elder people's quality of life in different socio-cultural and practice settings. The WHOQOLOLD-P utilization in future studies will also make comparison of cross-region and cross-border health status of elder people attainable and desirable.

\section{Abbreviations}

QOL: Quality of life; WHO: World Health Organization; WHOQOL-OLD: World Health Organization Quality of life-old module; AMTS: Abbreviated Mental Test Score; WHOQOL-OLD-P: World Health Organization Quality of life-old module for Persian-speaking population; CVI: Content validity index; CVR: Content validity ratio; ICC: Intra-Class Correlation; CFA: Confirmatory factor analysis; RMSEA: Root Mean Square Error of Approximation; SRMR: Standardized Root Mean Square Residual; CFI: Comparative Fit Index: TLI: Tucker Lewis index; HCPs: Healthcare Providers

\section{Acknowledgements}

The authors would like to express their sincere gratitude to the health care workers who helped the study participants' recruitment and data collection activities. Their special thanks will also go to older adults from the Muslim and Zoroastrian communities in the city of Yazd who participated in this study without which this would not have been possible.

\section{Authors' contributions}

All authors collectively contributed to intellectual content and conceived the original study concept and assisted in the design and appraisal of the findings. HR collected the study data, performed data analysis and interpretation and drafted the first version of the manuscript with receiving considerable help and advices from AM, MAM and AS. AS was the main grant applicant with major role in supervision of the whole research implementation, providing critical feedback and taking the lead in preparation of the final version. All authors discussed the results and commented on the manuscript and have approved the final version.

\section{Funding}

This study was partially funded by the Tabriz University of Medical Sciences, Tabriz, Iran.

\section{Availability of data and materials}

The datasets used and/or analyzed during the current study are available from the corresponding author on reasonable request.

\section{Ethics approval and consent to participate}

Ethical approval for conduct of this study was obtained from the Medical Ethics Board of Trustees (MEBT) in the Yazd University of Medical Sciences (approval number: IR.SSU.SPH.REC.1397.092). The purpose, methodology and voluntariness of participation in the study was explained for all of the respondents and they were assured about confidentiality of the collected data before signing the informed consent form.

\section{Consent for publication}

There are no materials, details or image of any individual within the manuscript that requires consent for publication.

\section{Competing interests}

The authors declare that they have no competing interests.

\section{Author details}

'Department of Health Education and Promotion, Faculty of Health, Tabriz University of Medical Sciences, Tabriz, Iran. ${ }^{2}$ Department of Aging Health, School of Public Health, Shahid Sadoughi University of Medical Sciences, Yazd, Iran. ${ }^{3}$ Health and Environment Research Center, Tabriz University of Medical Sciences, Tabriz, Iran.
Received: 15 December 2019 Accepted: 5 March 2020

Published online: 11 March 2020

\section{References}

1. Department of Health Human Services, USA. Multiple chronic conditions-a strategic framework: optimum health and quality of life for individuals with multiple chronic conditions. Washington, DC: US Department of Health and Human Services. 2010; 2.https://doi.org/10.1037/e507192011-001.

2. Kalfoss M, Halvorsrud L. Important issues to quality of life among Norwegian older adults: an exploratory study. Open Nurs J 2009;3:45-55. https://doi.org/10.2174/1874434600903010045.

3. Population and Housing Censuses 2016. Selected Findings of the 2016 National Population and Housing Census. [Internet]. 2018. Available from: https://www.amar.org.ir/Portals/1/census/2016/Census_2016_Selected_ Findings.pdf. [cited Oct 2018].

4. Bowling A Do older and younger people differ in their reported well-being? A national survey of adults in Britain. Fam Pract 2010;28(2):145-155.https:// doi.org/10.1093/fampra/cmq082.

5. World Health Organization Quality Of Life (WHOQOL) Group. Development of the WHOQOL: rationale and current status. Int J Ment Health 1994;23(3): 24-56.https://doi.org/10.1080/00207411.1994.11449286.

6. WHOqol Group. The World Health Organization quality of life assessment (WHOQOL): position paper from the World Health Organization. Soc Sci Med 1995:41(10):1403-1409.https://doi.org/10.1016/0277-9536(95)00112-k.

7. Evans S Quality of life measures in the elderly and later life. Handbook of Disease Burdens and Quality of Life Measures 2010:2649-65. https://doi.org/ 10.1007/978-0-387-78665-0_154.

8. Hyde $M$, Wiggins RD, Higgs $P$, Blane DB. A measure of quality of life in early old age: the theory, development and properties of a needs satisfaction model (CASP-19). Aging Ment Health 2003;7(3):186-194.https://doi.org/10. 1080/1360786031000101157.

9. Bowling A, Hankins M, Windle G, Bilotta C, Grant R. A short measure of quality of life in older age: the performance of the brief older People's quality of life questionnaire (OPQOL-brief). Arch Gerontol Geriatr 2013;56(1): 181-187. https://doi.org/10.1016/j.archger.2012.08.012.

10. Garratt A, Schmidt L, Mackintosh A, Fitzpatrick R. Quality of life measurement: bibliographic study of patient assessed health outcome measures. Br Med J 2002;324(7351):1417.https://doi.org/10.1136/bmj.324. 7351.1417.

11. Power M, Quinn K, Schmidt S. Development of the WHOQOL-old module Qual Life Res 2005;14(10):2197-2214.https://doi.org/10.1007/s11136-0057380-9.

12. Conrad I, Matschinger H, Riedel-Heller S, von Gottberg C, Kilian R. The psychometric properties of the German version of the WHOQOL-OLD in the German population aged 60 and older. Health Qual Life Outcomes 2014; 12(1):105.https://doi.org/10.1186/s12955-014-0105-4.

13. Chachamovich E, Fleck MP, Trentini C, Power M. Brazilian WHOQOL-OLD module version: a Rasch analysis of a new instrument. Rev Saude Publica 2008;42(2):308-316.https://doi.org/10.1590/s0034-89102008000200017.

14. Fleck MP, Chachamovich E, Trentini C. Development and validation of the Portuguese version of the WHOQOL-OLD module. Rev Saude Publica 2006; 40:785-791.https://doi.org/10.1590/s0034-89102006000600007.

15. Halvorsrud L, Kalfoss M, Diseth $\AA$. Reliability and validity of the Norwegian WHOQOL-OLD module. Scand J Caring Sci 2008;22(2):292-305.https://doi. org/10.1111/j.1471-6712.2007.00523.x.

16. Liu R, Wu S, Hao Y, Gu J, Fang J, Cai N, et al The Chinese version of the world health organization quality of life instrument-older adults module (WHOQOL-OLD): psychometric evaluation. Health Qual Life Outcomes 2013; 11(1):156.https://doi.org/10.1186/1477-7525-11-156.

17. Lucas-Carrasco R, Laidlaw K, Power MJ. Suitability of the WHOQOL-BREF and WHOQOL-OLD for Spanish older adults. Aging Ment Health 2011;15(5):595604.https://doi.org/10.1080/13607863.2010.548054

18. Leplege A, Perret-Guillaume C, Ecosse E, Hervy M, Ankri J. A new instrument to measure quality of life in older people: the French version of the WHOQOL-OLD. La Revue de Medecine Interne 2013;34(2):78-84.https://doi. org/10.1016/j.revmed.2012.07.011.

19. Eser S, Saatli G, Eser E, Baydur H, Fidaner C. The reliability and validity of the Turkish version of the World Health Organization quality of life instrumentolder adults module (WHOQOL-old). Turk Psikiyatri Dergisi. 2010;21(1):1. 
20. Yong $A G$, Pearce $S$. A beginner's guide to factor analysis: focusing on exploratory factor analysis. Tutorials Quant Methods Psychol 2013;9(2):79-94. https://doi.org/10.20982/tqmp.09.2.p079.

21. Bakhtiyari F, Foroughan M, Fakhrzadeh H, Nazari N, Najafi B, Alizadeh M, et al. Validation of the persian version of abbreviated mental test (AMT) in elderly residents of Kahrizak charity foundation. Iran J Diabetes Metab. 2014; 13(6):487-94.

22. Bullinger $\mathrm{M}$, Alonso J, Apolone $\mathrm{G}$, Leplège $\mathrm{A}$, Sullivan $\mathrm{M}$, Wood-Dauphinee $S$, et al Translating health status questionnaires and evaluating their quality: the IQOLA project approach. J Clin Epidemiol 1998;51(11):913-923.https:// doi.org/10.1016/s0895-4356(98)00082-1.

23. Sartorius N, Kuyken W. Translation of health status instruments. Quality of life assessment: International Perspectives: Springer; 1994. p. 3-18.https:// doi.org/10.1007/978-3-642-79123-9_1.

24. Polit DF, Beck CT. The content validity index: are you sure you know what's being reported? Critique and recommendations. Res Nurs Health 2006;29(5): 489-497.https://doi.org/10.1002/nur.20147.

25. Lawshe CH. A quantitative approach to content validity. Pers Psychol 1975; 28(4):563-575.https://doi.org/10.1111/j.1744-6570.1975.tb01393.x.

26. Abbott ML. Using statistics in the social and health sciences with SPSS and excel: John Wiley \& Sons, Inc, Hoboken, New Jersey; 2017.

27. Nunnally JC. Psychometric theory 3E: Tata McGraw-hill education; 1994.

28. Koo TK, Li MY. A guideline of selecting and reporting intraclass correlation coefficients for reliability research. J Chiropr Med 2016;15(2):155-163.https:// doi.org/10.1016/j.jcm.2016.02.012.

29. Hu Lt, Bentler PM. Cutoff criteria for fit indexes in covariance structure analysis: conventional criteria versus new alternatives. Struct Equ Model Multidiscip J 1999;6(1):1-55.https://doi.org/10.1080/10705519909540118.

30. IBM Corp. IBM SPSS statistics for windows, version 24.0. Armonk, NY: IBM Corp. 2016.

31. StataCorp. Stata Statistical Software: Release 14. College Station, TX: StataCorp LP. 2015https://doi.org/10.7717/peerj.4598/supp-10.

32. Van Biljon L, Nel P, Roos V. A partial validation of the WHOQOL-OLD in a sample of older people in South Africa. Glob Health Action 2015;8(1):28209. https://doi.org/10.3402/gha.v8.28209.

33. Peel NM, Bartlett HP, Marshall AL. Measuring quality of life in older people: reliability and validity of WHOQOL-OLD. Australas J Ageing 2007;26(4):162167.https://doi.org/10.1111/j.1741-6612.2007.00249.x.

34. Streiner DL, Norman GR, Cairney J. Health measurement scales: a practical guide to their development and use: Oxford University press, USA; 2015.

35. Haywood K, Garratt A, Fitzpatrick R. Quality of life in older people: a structured review of generic self-assessed health instruments. Qual Life Res 2005;14(7):1651-1668.https://doi.org/10.1007/s11136-005-1743-0

36. De Vaus D. Analyzing social science data: 50 key problems in data analysis: sage; 2002.

37. Gobbens RJ, van Assen MA. Psychometric properties of the Dutch WHOQOL-OLD. Health Qual Life Outcomes 2016;14(1):103.https://doi.org/10. 1186/s12955-016-0508-5.

38. Sivertsen H, Bjørkløf GH, Engedal K, Selbæk G, Helvik A-S. Depression and quality of life in older persons: a review. Dement Geriatr Cogn Disord 2015; 40(5-6):311-339. https://doi.org/10.1159/000437299.

39. Kreitler SH, Kreitler MM. Multidimensional quality of life: a new measure of quality of life in adults. Soc Indic Res 2006;76(1):5-33.https://doi.org/10. 1007/s11205-005-4854-7.

\section{Publisher's Note}

Springer Nature remains neutral with regard to jurisdictional claims in published maps and institutional affiliations.

\section{Ready to submit your research? Choose BMC and benefit from:}

- fast, convenient online submission

- thorough peer review by experienced researchers in your field

- rapid publication on acceptance

- support for research data, including large and complex data types

- gold Open Access which fosters wider collaboration and increased citations

- maximum visibility for your research: over $100 \mathrm{M}$ website views per year

At BMC, research is always in progress.

Learn more biomedcentral.com/submissions 